\title{
Acromegaloid facial appearance syndrome
}

INSERM

\section{Source}

INSERM. (1999). Orphanet: an online rare disease and orphan drug data base. Acromegaloid facial appearance syndrome. ORPHA:965

Acromegaloid facial appearance (AFA) syndrome is a multiple congenital anomalies/dysmorphic syndrome (see this term) with a probable autosomal dominant inheritance, characterized by a progressively coarse acromegaloid-like facial appearance with thickening of the lips and intraoral mucosa, large and doughy hands and, in some cases, developmental delay. AFA syndrome appears to be part of a phenotypic spectrum that includes hypertrichotic osteochondrodysplasia, Cantu type and hypertrichosisacromegaloid facial appearance syndrome (see these terms). 